(RESEARCH ARTICLE)

\title{
Effects of computer-assisted instruction on students' achievement in atomic and nuclear physics in Senior Secondary Schools in Rivers State
}

\author{
Adolphus T and Omeodu $\mathrm{M}^{*}$ \\ Department of Science Education Faculty of Education Rivers State University. \\ Publication history: Received on 24 February 2020; revised on 04 March 2020; accepted on 06 March 2020
}

Article DOI: https://doi.org/10.30574/gscarr.2020.2.3.0015

\begin{abstract}
The study examined the Effects of computer-Assisted Instruction (CAI) on students' achievement in Atomic and Nuclear Physics in Rivers state. The objective of the study was to determine the difference in the academic achievement Physics students when taught atomic and nuclear physics with CAI and lecture method. The study adopted pretest-posttest design of quasi-experimental research. The study was carried out in Rivers state senior secondary schools. The population of the study comprised of all senior secondary school 3 physics students in Rivers state. The sample size of the study was drawn using purposive random sampling. The total sample size of the study was one hundred and twenty (120). The sample size was grouped to control (60) and experimental groups (60). The instrument used for the study was an achievement test which was tagged "Atomic and Nuclear Physic Achievement Test (ANPAT)". The instrument consisted 40 Multiple Choice Question (MCQ). The instrument was sectioned into four parts, each section measured students' knowledge on the models of atom, energy quantization, photoelectric emission and thermionic emission. The reliability of the instrument was tested using test-retest method which yielded 0.88 reliability coefficient. Mean and standard deviation was used for data analysis while t-test was used to test the hypotheses at 0.05 level of significance. It was found that students that were taught atomic and nuclear physics with CAI (60.5) have higher mean achievement scores than those taught with lecture method (44.1). This implies that students taught atomic and nuclear physics using computer assisted instruction performed better than those taught with lecture method. The t-test analysis also showed that the differences that exist in the mean are statistically significant at 0.05 . Thus, the study recommended that government should assist the schools to make adequate computers available for teaching and learning physics in secondary schools.
\end{abstract}

Keywords: Computer; Assisted; Instruction; Achievement; Students; Physics

\section{Introduction}

Mode of instruction delivery has taken a quantum leap with emergence of computing technologies in teaching and learning. Over the years, traditional method teaching was a common mode of instruction delivery since there were no available facilities for effectiveness in demonstrating physics concept at disposal. However, the emergence of computing technologies for teaching and learning moderated the lapses by making necessary pictorial views and animations available to properly demonstrate abstract concepts. Although the use of computer in instruction delivery has been developing for over 40 years in the developed countries [1], its use in the developing world just gained ascendance a decade ago.

Computer Assisted instruction is a new approach in the field of education that comprises the use of computer technologies in instructional delivery. Nazimuddin [2] described CAI as "a diverse and rapidly expanding spectrum of computer technologies that assist the teaching and learning process". CAI is seen as a method of instruction which

\footnotetext{
${ }^{*}$ Corresponding author

E-mail address: didijond@yahoo.co.nz
} 
involves the use of computer to provide instructional contents" [3], allows for interaction between user and computer with immediate feedback [4]. Computer-assisted instruction (CAI) is an approach of instructional delivery whereby computer is used to communicate the instructional materials and evaluate the learning outcomes [5]. It uses a blend of graphs, texts, sounds and videos for learning process [6]. Computer assisted instruction could therefore be described as the utilization of computing technologies in classroom instructional delivery. The use of computing technologies in school is rapidly taking over the traditional approaches to learning. This computer trend had made schools to see necessity and not luxury in acquiring computer for teaching and learning process especially in the developing countries.

Computer assisted instruction has been proved to be an effective mode of instructional delivery that facilitate students' learning process. Various scholarly researches supported that learners who are taught using computers have extensive self-assurance, confidence and are more efficacious and are highly interested to learn than those learners who are subjected to learn in traditional learning environment [7]. Agah and Gunduz [8] in their studies found that students achieve more at all level of cognitive development when taught using CAI than that of traditional mode of teaching. Significant increase in the use of computers and mobile services among schools and individuals proved the extent to which computer is widely adopted for instructional delivery. According to Gana [9] expressed that CAI is learner-centered and activity oriented mode of instruction. This implies that CAI is a kind of instruction that actively engage learners' senses and cognitive reasoning while learning.

Studies have revealed that the more senses of the body are actively utilized in the presentation of concepts (sound, picture, text, animation etc.) in education, the longer the content remains in the brain and the faster learning is accomplished [8]. Because computer assisted instruction enhances the ability of individuals to learn, it entail that concepts should be learnt not through memorization as in the traditional instruction but through conceiving them [10]. In language learning, Chera and Wood [11] assert that CAI was used to promote phonological awareness, experimental group of the study showed significantly higher increase in phonological awareness than their counterparts.

The utilization of computer technologies for teaching takes various forms. However, For the purposes of this study, "CAI refers to mode of instruction in which a student directly interacts with a computer and learns through lessons programmed into the computer" [12]. Computer and related technologies are used for instructional delivery. According to Gana [9] CAI could be virtually any sort of computer application in instructional settings comprising of drill and practice, simulations, instructional exercises, supplementary exercises, instructional management, database development, programming, composing using word processors, and other different applications. CAI according to Bhalla [12] could be categorized into any of the following;

Table 1 Computer Assisted instruction (Ways and Description)

\begin{tabular}{|c|c|}
\hline \multicolumn{2}{|r|}{ Computer Assisted instruction } \\
\hline Ways & Description \\
\hline Tutorials & $\begin{array}{l}\text { Present information ask questions, monitor responses, provide feedback, keep } \\
\text { records }\end{array}$ \\
\hline Drills and Practice & $\begin{array}{l}\text { Present item to work on, provide feedback on correctness and notes on incorrect } \\
\text { responses, summarize results. }\end{array}$ \\
\hline Simulation & $\begin{array}{l}\text { Approximate real-life situations, control expense, access „inaccessible", perform } \\
\text { operations. }\end{array}$ \\
\hline Gaming & Computer acts as competitor, judge, and scorekeeper in motivational format \\
\hline Problem solving & $\begin{array}{l}\text { Solve basic problems related to calculation, experiment, exploration; maintain } \\
\text { database }\end{array}$ \\
\hline
\end{tabular}

Computer usage for teaching and learning varies with the teacher and the objectives of the instruction. Some teachers really utilize computer technologies for instructional delivery when there is need to enhance open expression and interaction with the students. In this case, internet social media platform and other online discussion forums could be used. However, in classroom learning when both teachers are students are present, CAI could take the form of powerpoint presentation, pictures and image display through the overhead projector, animation and simulation and other educational software. This helps to visually engage students to create pictures and imaginations of what is been taught. Nazimuddin [2] noted that information that helps teach or encourages interaction can be presented on 
computers in the form of text or in multimedia formats, which include photographs, videos, animation, speech, and music. He further explained that CAI is successful in raising examination scores, improving student attitudes, and lowering the amount of time required to master certain material. In this regards, utilization of CAI in physics gives numerous options to students, for example, visualization of abstract concepts that will stimulate students' understanding [13].

Physics is the branch of pure science that deals with the structure of matter and how the fundamental constituents of the universe interact. It has many branches that include mechanics, optics, heat, electricity, magnetism, nuclear physics, solar energy, etc. However, for the purpose of the study, nuclear physics is only considered. Nuclear physics is a physics of atomic nuclei and their constituents and interaction. WAEC syllabus [14] atomic and nuclear physics are categorized into models of the atoms, energy quantization, photoelectric effects and thermionic emission. In this units students are expected to know atomic structure (nuclei) and its various interaction. Models of atoms entails the various concepts on atomic structure and the composition. Atoms are described based on perspective of different scientists such as John Dalton, Ernest Rutherford, Neils Bohr among others. Energy quantization entails the description of energy absorption or emission in discreet packets or quanta. It is a concept that proposed that energy is quantized in some systems and those systems can have certain energies and not a continuum of energies. Photoelectric effects deals with the emission /reaction of an electron when light hits a material. Thermionic emission refers to the reaction of atomic component when on a heated source. It basically describe the emission of an electron from a heated source. Atomic and nuclear physics tend to equip learners with the various reaction of matters to energy.

Over the years, records have shown that students' performance in physics is extremely on the low side as large number of students seems to display competencies in the basic concept of Physics. This is evident as Nwanne and Agommuoh [15] noted that Nigerian candidates trailed behind their counterparts from other countries in the West African region based on performance in science subjects (physics) conducted by the West African Examinations Council (WAEC). This deficiency has been attributed to many factors, and inappropriate teaching method to convey physics concepts to learners is mainly inclusive [16]. Nevertheless, researches have indicated that improving on the techniques of instructional delivery will help to resolve this deficiency significantly. It is in this regard, that the study tends to determine the effects of computer assisted instruction on students' achievement in atomic and nuclear physics in Rivers state secondary schools.

\section{Purpose of the study}

The purpose of the study is to determine the effects of computer-Assisted instruction on students' achievement and retention in Atomic and nuclear physics in Rivers state. In specific terms, the study sought to;

- Determine the difference in students' academic performance in models of the atom when taught using computer aided instruction and conventional method?

- Determine the difference in students' academic performance in energy quantization when taught using computer aided instruction and conventional method?

- Determine the difference in students' academic performance in photoelectric effect when taught using computer aided instruction and conventional method?

- Determine the difference in students' academic performance in thermionic emission when taught using computer aided instruction and conventional method.

\section{Research Questions}

The study seeks to proffer answer to the following questions

- What is the difference in students' academic performance in models of the atom when taught using computer aided instruction and conventional method?

- What is the difference in students' academic performance in energy quantization when taught using computer aided instruction and conventional method?

- What is the difference in students' academic performance in photoelectric effect when taught using computer aided instruction and conventional method?

- What is the difference in students' academic performance in thermionic emission when taught using computer aided instruction and conventional method. 


\section{Methodology}

The study adopted pretest-posttest design of the quasi-experimental research. This means that the effects of experimental and control group will be tested against each other. The study was carried out in Rivers state senior secondary schools. The population of the study comprised of all senior secondary school 3 physics students in Rivers state. However, the sample size of the study was drawn using purposive random sampling. Six schools, two each from the three senatorial zones were purposively sampled based on the availability of adequate computers for teaching and learning. In each of the schools twenty (20) S.S 3 students were randomly selected using balloting. The total sample size of the study was one hundred and twenty (120) which were 68 males and 52 females. The total sample size (120) was randomly split into two halves each half contained sixty (60) respondents. These groups was tagged control and experimental groups. The control group were taught with lecture method while the counterpart (experimental group) were instructed using computer assisted instruction. Computer simulations, animations, picture, powerpoint and video clips were engaged in the lesson delivery as the treatment for experimental group. The instrument used for the study was an achievement test which was tagged "Atomic and Nuclear Physic Achievement test (ANPAT)". The instrument consisted 40 multiple choice question (MCQ). The instrument was sectioned into four parts, each section measured students' knowledge and understanding on the models of atom, energy quantization, photoelectric emission and thermionic emission. Each questions in the instrument carries 2 marks. The reliability of the instrument was tested using test-retest method which yielded 0.88 reliability coefficient. Mean and standard deviation was used for data analysis while t-test was used to test the hypotheses at 0.05 level of significance.

\section{Results}

\subsection{Research question 1}

What is the difference in students' academic performance when taught atomic and nuclear physics with computer aided instruction and conventional method?

Table 2 Mean difference in the academic performance of students taught atomic and nuclear physics with computer aided instruction and conventional method.

\begin{tabular}{|c|c|c|c|c|c|c|c|}
\hline & \multicolumn{2}{|c|}{ Pre-test } & \multicolumn{2}{|c|}{ Post-test } & \multirow[t]{2}{*}{ Mean gain } & \multicolumn{2}{|c|}{ T-test ( 0.05 lev. of sig.) } \\
\hline & Mean & S.D & Mean & S.D & & T-cal & $\mathrm{R} /$ mark \\
\hline CAI & 33.23 & 7.04 & 60.5 & 6.60 & 27.27 & 21.88 & Sig. \\
\hline Lecture Method & 32.36 & 6.54 & 44.1 & 6.00 & 11.74 & 10.24 & Sig. \\
\hline Mean diff. & 0.87 & 0.50 & 16.4 & 0.60 & & & \\
\hline Test of sig. (t-test) & \multicolumn{2}{|c|}{0.70} & \multicolumn{2}{|c|}{14.24} & & & \\
\hline
\end{tabular}

Table 1 shows the difference in students' academic performance when taught atomic and nuclear physics with computer aided instruction and conventional method. It was revealed that the mean difference in the pre-test of experimental (33.23) and control groups (32.36) was 0.87 which was confirmed not significant when subjected to ttest $(\mathrm{t}$-cal $=0.70<\mathrm{t}$-crit=1.98). The post-test mean score obtained in the experimental group was 60.4 while control group had 44.1 The mean difference obtained 16.4 which was subjected to test of significance using t-test. The result obtained ( $\mathrm{t}$-cal=14.24 > t-crit=1.98) indicated that there is a significant difference between the post test scores of the students taught atomic and nuclear physics. The students taught with computer assisted instruction performed better than those taught with lecture method. The mean difference obtained from the pretest and post test scores of the both experimental and control group was 27.27 and 11.74 respectively.

\subsection{Research Question 2}

What is the difference in students' academic performance when taught models of the atom using computer aided instruction and conventional method? 
Table 3 Students' academic performance when taught models of the atom using computer aided instruction and conventional method.

\begin{tabular}{|c|c|c|c|c|c|c|c|}
\hline & \multicolumn{2}{|c|}{ Pre-test } & \multicolumn{2}{|c|}{ Post-test } & \multirow[t]{2}{*}{ Mean gain } & \multicolumn{2}{|c|}{ T-test ( 0.05 lev. of sig.) } \\
\hline & Mean & S.D & Mean & S.D & & T-cal & $\mathrm{R} /$ mark \\
\hline CAI & 8.63 & 3.42 & 14.93 & 3.40 & 6.3 & 10.12 & Sig. \\
\hline Lecture Method & 8.20 & 3.03 & 10.07 & 3.27 & 1.87 & 3.25 & Sig. \\
\hline Mean diff. & 0.42 & 0.39 & 4.86 & 0.13 & & & \\
\hline Test of sig. (t-test) & \multicolumn{2}{|c|}{0.73} & 7.98 & & & & \\
\hline
\end{tabular}

The table 2 shows the difference in students' academic performance when taught models of the atom using computer aided instruction and conventional method. It was revealed that the mean difference in the pre-test of both experimental and control groups was 0.42 which was confirmed not significant when subjected to t-test $(\mathrm{t}$-cal $=0.73>$ $\mathrm{t}$-crit= 1.98). The mean scores of the both groups (experimental and control) after treatment was $14.93 \& 10.04$ respectively. The mean difference in the post-test scores of both group was 4.86 in favour of the experimental group. However, $\mathrm{t}$-test ( $\mathrm{t}$-cal=7.98 $>\mathrm{t}$-crit= 1.98) affirmed that the difference between the post-test scores of both groups were statistically significant. Also, the difference that existed between the mean of the pretest (8.64) and post-test (14.93) of the experimental group was 6.3 which was confirmed to be statistically significant at 0.05 level of significance $(\mathrm{t}$-cal $=10.12>\mathrm{t}$-crit $=1.98)$. In the control group, the pretest mean score was $(8.20)$ while the post-test mean score was (10.07), the mean difference (1.87) was subjected to test of significance and $3.25 \mathrm{t}$-cal value was established which also proved the significance of the mean difference.

\subsection{Research Question 3}

What is the difference in students' academic performance when taught energy quantization using computer aided instruction and conventional method?

Table 4 Students' academic performance when taught energy quantization using computer aided instruction and conventional method.

\begin{tabular}{llllllll}
\hline & Pre-test & \multicolumn{3}{c}{ Post-test } & & Mean gain & \multicolumn{2}{c}{ T-test (0.05 lev. of sig) } \\
\hline & Mean & S.D & Mean & S.D & & T-cal & Remark \\
CAI & 8.47 & 3.29 & 15.13 & 3.08 & 6.66 & 11.84 & Sig. \\
Lecture Method & 8.17 & 3.06 & 11.07 & 2.82 & 2.9 & 5.40 & Sig. \\
Mean diff. & 0.30 & 0.23 & 4.06 & 0.26 & & \\
\hline Test of Sig. (T-test) & $\mathbf{0 . 5 1}$ & \multicolumn{7}{c}{$\mathbf{7 . 5 3}$} \\
\hline \multicolumn{7}{c}{ Field Survey, 2019. }
\end{tabular}

Table 3 presents the pre-test and post test scores of students when taught energy quantization using computer aided instruction and conventional method. In order to ascertain the level of knowledge of the student in energy quantization, the difference in the pretest mean score was 0.30 . This difference was subjected to test of significance and it was established that there is no significant difference in the pre-test scores of both groups on energy quantization ( $\mathrm{t}$-cal=0.51< $\mathrm{t}$-crit=1.98). However, after the treatment the mean difference in the post test scores obtained was 4.06 in favour of the experimental group. The significance of this difference was established using t-test ( $\mathrm{t}$-cal= $7.53>\mathrm{t}$-crit=1.98). This shows that there is significant difference in the achievement scores of students. The students that were taught using computer assisted instruction performed significantly better than those taught with lecture method.

\subsection{Research Question 4}

What is the difference in students' academic performance when taught photo-electric emission using computer aided instruction and conventional method? 
Table 5 Students' academic performance when taught photoelectric emission using computer aided instruction and conventional method.

\begin{tabular}{llllllll}
\hline & Pre-test & \multicolumn{3}{c}{ Post-test } & \multicolumn{2}{c}{ Mean diff } & \multicolumn{2}{c}{ T-test (t-crit=1.98) } \\
\hline & Mean & S.D & Mean & S.D & & T-cal & Remark \\
CAI & 8.30 & 3.30 & 15.60 & 3.09 & 7.30 & 12.51 & Sig. \\
Lecture method & 7.67 & 3.04 & 11.60 & 3.27 & 3.93 & 6.81 & Sig. \\
Mean diff. & 0.63 & 0.26 & 4.00 & 0.18 & & & \\
\hline Test of sig. (T-test) & $\mathbf{1 . 0 8}$ & \multicolumn{7}{c}{$\mathbf{6 . 8 9}$} \\
\hline
\end{tabular}

Table 4 presents the difference in students' academic performance when taught photo-electric emission using computer aided instruction and conventional method. The mean difference between the pre-test mean score of experimental group (8.30) and control group (7.67) was 0.63. This difference was tested for significance at 0.05 level, it was established that there was no significant difference in the pre-test scores of both groups $(\mathrm{t}$-cal=1.08 $<\mathrm{t}$-crit= 1.98). This implies that students in both groups are equivalent in their level of knowledge in photoelectric emission. In their post test scores, the mean difference obtained was 4.00, experimental group had 15.60 while the control had 11.60. The difference was also tested for significance and it was confirmed that the difference between the post test scores is statistically significant $(\mathrm{t}-\mathrm{cal}=6.89>\mathrm{t}$-crit $=1.98)$. This implies that students taught photoelectric emission using computer assisted instruction performed better that those taught with lecture method.

\subsection{Research question 5}

What is the difference in students' academic performance when taught thermionic emission using computer aided instruction and conventional method?

Table 6 Students' academic performance when taught thermionic emission using computer aided instruction and conventional method

\begin{tabular}{llllllll}
\hline & Pre-test & \multicolumn{3}{c}{ Post-test } & \multicolumn{2}{c}{ Mean gain } & \multicolumn{2}{c}{ T-Test (t-crit=1.98) } \\
\hline & Mean & S.D & Mean & S.D & & T-cal & Remark \\
CAI & 7.83 & 3.00 & 14.87 & 2.91 & 7.04 & 13.05 & Sig \\
Lecture method & 8.33 & 2.92 & 11.33 & 2.30 & 3.00 & 6.25 & Sig. \\
Mean difference & 0.5 & 0.08 & 3.54 & 0.61 & & & \\
Test of sig. (T-test) & 0.93 & \multicolumn{7}{c}{7.39} & & & & \\
\hline
\end{tabular}

Table 4 shows the difference in students' academic performance when taught thermionic emission using computer aided instruction and conventional method, The mean difference of both groups was 0.5 , experimental group with mean of 7.33 and control group had 8.33. The difference in the pre-test score was subjected to test of significance using t-test. It therefore established that there is no significant difference between the pre-test scores of both groups at 0.05 level of significance ( $\mathrm{t}$-cal $=0.93<\mathrm{t}$-cal= 1.98). In their post test scores, the mean difference obtained was 3.54 , experimental group had 14.87 while the control had 11.33. The difference was also tested for significance and it was confirmed that the difference between the post test scores is statistically significant $(t-c a l=7.39>t$-crit $=1.98)$. This implies that students taught thermionic emission using computer assisted instruction performed better that those taught with lecture method.

\section{Discussion of findings}

The findings of the study in table 1 shows the overall mean and standard deviation scores of the students in ANPAT. It was found that students that were taught atomic and nuclear physics with CAI (60.5) have higher mean achievement scores than those taught with lecture method (44.1) revealed that students taught atomic and nuclear physics using computer assisted instruction performed better than those taught with lecture method. The t-test analysis also 
showed that the differences that exist in the mean are statistically significant at 0.05 ( $\mathrm{t}$-cal= $14.24>\mathrm{t}$-crit=1.98). The finding is in line with [15] who observed that CAI improved students' achievement and interest in physics than the lecture teaching methods. They further posited that "CAI is a viable alternative to the conventional lecture teaching methods in teaching physics". Moreover, CAI provides powerful tools to support the shift to student-centered learning and is capable of creating a more interactive and engaging learning environment for teachers and learners. This finding is in agreement with the result of [8], in their study they found that students achieve more at all level of cognitive development when taught using CAI than that of traditional mode of teaching.

\section{Conclusion}

Computer Assisted instruction (CAI) is a veritable method of delivery instruction to maximize students' achievement in Physics. Since most concepts in physics are abstract, students tends to be bored and indifferent while learning. However, the utilization of computer assisted instruction is found to be effective to ameliorate this deficiency. CAI encourage student-centered learning and help learners to be more interactive by engaging their active senses to learning.

\section{Recommendation}

- Government should assist the schools to make adequate computers available for teaching and learning Physics in secondary schools.

- Secondary school Physics teachers should be trained on the effective utilization of computer technologies for carrying teaching and learning process.

- School administrators should encourage teachers to always utilize modern computer technologies in the teaching of Physics

\section{Compliance with ethical standards}

\section{Disclosure of conflict of interest}

Both authors declare that they have no conflict of interest for publishing this article.

\section{References}

[1] Liao Y. (2004). Effects of computer-assisted instruction on students' achievement in Taiwan: A meta-analysis. Computers \& Education, 48, 216-233.

[2] Nazimuddin SK. (2014). Computer Assisted Instruction (CAI): A new approach in the field of education. International Journal of Scientific Engineering and Research (IJSER), 3 (7), 185-188.

[3] Seo Y and Bryant P. (2009). Analysis of studies of the effects of computer-assisted instruction on the mathematics performance of students with learning disabilities. Computers \& Education, 53, 913-928.

[4] Bennett S. (2012). The effects of Computer Assisted Instruction on rural Algebra I Students.

[5] Qaiser S, Hussain I, Ud Din N and Iqbal K. (2017). Effects of Computer-Assisted Instruction (CAI) on Students' Academic Achievement in Physics at Secondary Level. Computer Engineering and Intelligent Systems, 8 (7), 918.

[6] Onasanya SA, Daramola FO and Asuquo EN. (2006). Effect of Computer Assisted Instructional Package on Secondary School Students' Achievement in Introductory Technology in Ilorin, Nigerian. The Nigeria Journal of Educational Media and Technology, 12(1), 98-107.

[7] Wishart J. (2002). Students and Teacher's Motivation and Learning through Use of CD -ROMs. Journal of Multimedia and Hypermedia, 9(4), 333-47.

[8] Agah TG and Gunduz S. (2011). The effects of computer assisted instruction practices in computer office program course on academic achievements and attitudes toward computer. Procedia Social and Behavioral Sciences, 15, 1931-1935.

[9] Gana CS. (2013). Effects of Computer Assisted Instruction with Animation on Achievement and Retention of Students of Colleges of Education in Quantum Physics. Unpublished PhD Thesis, Department of Science Education, University of Nigeria, Nsukka. 
[10] Bartlett RM, Cheng S and Strough J. (2000). Multimedia versus traditional course instruction in undergraduate introductory psychology. Poster presented at Annual American Psychological Association.

[11] Chera PDK and Wood C. (2003). 'Animated multimedia 'talking books' can promote phonological awareness in children beginning to read' Learning and Instruction, 13, 33-52.

[12] Bhalla J. (2013). Computer Use by School Teachers in Teaching-learning Process. Journal of Education and Training Studies, 1(2), 174-186.

[13] Meltzer DE and Manivannan K. (2002). Transforming the lecture-hall environment: The fully interactive physics lecture. American Journal of Physics, 70(6), 639-654.

[14] WAEC. (2019). West African Examination Council syllabus.

[15] Nwanne SC and Agommuoh PC. (2017). Computer Assisted Instruction (Cai) On Students' Interest And Achievement In Physics In Imo State, Nigeria. IOSR Journal of Research \& Method in Education (IOSR-JRME), 7 (3), 53-58.

[16] Okebukola. (2007). Workshop Organisation, Safety and Gender Equality in TVE at Secondary Education Level. A paper presented at 2008 Serminar/workshop Services of Nigerian Association of Teachers of Technology (NATT). Held at Federal College of Education (Technical). Akoka.

\section{How to cite this article}

Adolphus T and Omeodu M. (2020). Effects of Computer-Assisted Instruction on Students' Achievement in Atomic and Nuclear Physics in Senior Secondary Schools in Rivers State. GSC Advanced Research and Reviews, 2(3), 01-08. 